\title{
Vid2U: facilitating students' learning through video annotation for tablet device
}

\begin{abstract}
Electronic learning (e-learning) applications are widely used in the Higher-Education institutions to deliver and share learning contents among the students. However, most of the e-learning applications are developed for offline or online desktops. Mobile learning (mlearning) is introduced to allow learners to experience the learning opportunities via mobile devices such as handheld computers, MP3 players, notebooks, mobile phones, and tablets. Interactive video refers to a technique which allows users to have some interactions with the media instead of watching a static video. One of the many ways of making video having the interactive elements is through video annotation. Although the use of video annotation is quite common in learning, there are still needs for more efforts on designing annotation facilities for video management in mobile learning environment. Apart from that, the application of video annotation on mobile devices is also still in its infancy, especially for recent devices like iPad, Microsoft Surface, Samsung Galaxy Tab, and others. The objective of the proposed mobile learning application, Vid2U is to provide the flexibility of accessing and managing video materials at anywhere and anytime, making learning even more widely available. The Vid2U is equipped with many functions such as allowing students to view lecture videos and other video materials related to the course when absent from classes. Students can also add, edit, and delete their lecture notes based on the lecture videos. The mobile-based application also allows students to search video materials related to all courses taken by them. Experimental results obtained from surveys have shown that the Vid2U is able to provide better learning environment for the university learners, which lead to a deeper level of learning engagement.
\end{abstract}

Keyword: Annotation; Notes-Taking; Tablet; Video; m-Learning 